\title{
NUEVAS DINÁMICAS EN LAS RELACIONES ENTRE CRIMEN ORGANIZADO Y GRUPOS TERRORISTAS
}

\author{
Inmaculada MARRERO RochA*
}

SUMARIO: 1 . INTRODUCCIÓN.-2. SIMILITUDES Y DIFERENCIAS ENTRE GRUPOS DE CRIMINALES ORGANIZADOS Y GRUPOS TERRORISTAS.-3. FACTORES DE LA COOPERACIÓN ENTRE GRUPOS DE CRIMINALES ORGANIZADOS Y GRUPOS TERRORISTAS.-3.1. La financiación de los grupos terroristas.-3.2. La descentralización de las organizaciones terroristas y los grupos de criminales organizados.-3.3. Estados frágiles y cambios en la conflictividad armada.-4. MODELOS DE COOPERACIÓN ENTRE CRIMEN ORGANIZADO Y GRUPOS TERRORISTAS.-5. CONCLUSIONES.

\section{INTRODUCCIÓN}

1. Los cambios experimentados por la sociedad internacional, especialmente debido al proceso de globalización, han potenciado la participación de actores no estatales violentos (ANEV) en las relaciones internacionales, como son los grupos terroristas y las organizaciones criminales ${ }^{1}$. Los ANEV

* Este trabajo ha sido financiado por el Ministerio de Economía y Competitividad Español y por el Fondo Europeo de Desarrollo Regional (MINECO/FEDER) en el marco del Proyecto de Investigación con Referencia DER2015-63857-R y por el Proyecto Europeo TAKEDOWM (700688-H2020 FCT-162015). Inmaculada Marrero Rocha es profesora titular de Relaciones Internacionales en la Universidad de Granada (marrero@ugr.es). Todas las páginas web de referencia han sido consultadas por última vez el 2 de junio de 2017.

${ }^{1}$ Los ANEV son, según Ulrich Schneckener, aquellos que están dispuestos a utilizar la violencia para conseguir sus objetivos, sin ser parte de las instituciones del Estado, como guerrillas o grupos rebeldes, milicias, clanes armados, señores de la guerra, mercenarios y empresas militares o de seguridad privada. Los grupos rebeldes y las guerrillas persiguen la liberación de una clase social o de una «nación», por lo que cuentan con una agenda política revolucionaria o nacionalista-étnica, y se reconocen a sí mismos como el futuro ejército de la población a la que pretenden liberar. Las milicias o paramilitares son grupos de combatientes irregulares que normalmente son tolerados por los gobiernos y, en ocasiones, auspiciados por las autoridades, porque luchan contra las fuerzas rebeldes o los opositores. Los clanes y sus jefes son grupos tribales, grupos étnicos o comunidades religiosas que gobiernan, conforme a sus leyes y tradiciones, en la parte del territorio en la que se han establecido con un reconocimiento formal o informal del gobierno, y cuentan con miembros armados de su grupo para defenderles. Los señores de la guerra son potentados locales que controlan parte del territorio durante y después del conflicto armado. Su poder se basa en el control de los recursos naturales y en la creación de un ejército privado que defienda sus intereses (ScHNECKENER, U., "Fragile Statehood, 
también establecen sus propias relaciones de cooperación, que no se sustentan en los principios y las normas de Derecho internacional, sino que, por el contrario, se sitúan en un plano de ilegalidad e inmoralidad ${ }^{2}$.

2. El objeto de este estudio es analizar las circunstancias y factores que facilitan la cooperación entre grupos terroristas y grupos de criminales organizados, especialmente en contextos de fragilidad estatal, donde la intensidad y modalidades de relaciones presentan una serie de particularidades. Los análisis sobre la cooperación entre terroristas y criminales organizados no se justifican por su novedad, ya que en décadas anteriores esas relaciones fueron constatadas a partir de estudios de casos. Pero sí que reviste interés la evolución de su naturaleza e intensidad como consecuencia de los cambios que ha sufrido el sistema internacional ${ }^{3}$. Además, cada vez son más las instituciones y organismos nacionales e internacionales que relacionan las actividades del crimen organizado con las de los grupos terroristas internacionales, proponiendo estrategias integradas para hacerles frente ${ }^{4}$.

3. A lo largo de estas páginas se analizarán las similitudes y diferencias entre el crimen organizado y los grupos terroristas como condicionantes de las relaciones que puedan establecerse entre ambos. Igualmente, se examinarán los factores que han contribuido a transformar la naturaleza y el alcance de sus procesos de cooperación, tales como la lucha contra la financiación del

Armed Non-State Actors and Security Governance», Private Actors and Security Governance, vol. 4, 2006, pp. 23-40, pp. 25-28).

2 El Consejo de Seguridad señaló en la Resolución 2196(2014) su preocupación por los atentados perpetrados contra el personal de Naciones Unidas, incluidos aquellos de los que se beneficia la delincuencia transnacional organizada [S/RES/2196(2014), p. 3]. Esta interrelación entre crimen y terrorismo la pusieron de manifiesto, en 2011, más de 250 representantes de 90 países que se reunieron en Viena los días 16 y 17 de marzo en un simposio organizado por la Oficina de Naciones Unidas contra la Droga y el Delito (https://www.unodc.org/lpo-brazil/es/).

3 Schmid, A., «The Links Between Transnational Organized Crime and Terrorist Crimes», Transnational Organized Crime, vol. 2, 1996, pp. 40-82; DE BoER, J. y BosetTI, L., "The Crime-Conflict "Nexus": State of the Evidence», UNU-CPR Occasional Paper, vol. 5, 2015 (http://collections.unu.edu/ eserv/UNU:3134/unu_cpr_crime_conflict_nexus.pdf), y Kessels, E. y HenNEssy, O., "Examining the Nexus between Terrorism and Organized Crime: Linkages, Enablers and Policy Implications», en Glaser, H. (ed.), Talking to the Enemy: Deradicalization and Disengagement of Terrorists, Berlín, Nomos Verlag, 2017, pp. 233-254.

${ }^{4}$ Un ejemplo de ello es el Southeastern European Cooperative Initiative (SECI), organización multilateral con sede en Bucarest, que cuenta con una unidad especializada en las conexiones entre crimen organizado y terrorismo, especialmente en la zona de la antigua Yugoslavia. La Oficina Europea de Policía (EUROPOL), en su último informe SOFTA, «EU Serious and Organised Threat Assessment de 2017» alertó sobre las relaciones entre organizaciones criminales europeas y grupos terroristas (https:// www.europol.europa.eu/activities-services/main-reports/european-union-serious-and-organised-crimethreat-assessment-2017, pp. 55 y ss.). Recientemente, la Unión Europea ha alertado sobre los nuevos vínculos entre terrorismo y criminalidad organizada en su Directiva (UE) 2017/541, del Parlamento Europeo y del Consejo, de 15 de marzo, relativa a la lucha contra el terrorismo, y por la que se sustituye la Decisión marco 2002/475/JAI, del Consejo y se modifica la Decisión 2005/671/JAI, del Consejo (DO L 88/6, de 31 de marzo de 2017, considerando 21). En el caso español, en 2014, el Ministerio del Interior creó el Centro de Inteligencia contra el Terrorismo y el Crimen Organizado (CITCO) en la Secretaría de Estado de Seguridad del Ministerio del Interior, mediante la integración del Centro Nacional de Coordinación Antiterrorista (CNCA) y del Centro de Inteligencia contra el Crimen Organizado (CICO), lo que pone de manifiesto la necesidad de empezar a tratar las relaciones entre crimen organizado y terrorismo como una amenaza. 
terrorismo, el impacto de las diferentes dinámicas del proceso de globalización o los contextos de Estados frágiles o fallidos. Finalmente, se abordará el estudio de la tipología de relaciones de cooperación que desarrollan ambos actores en la actualidad.

4. El estudio se enmarca en la disciplina de las Relaciones Internacionales y para su desarrollo se hará una revisión de los análisis doctrinales que, de manera directa o tangencial, han identificado relaciones entre crimen organizado y grupos terroristas. Al mismo tiempo, examinaremos algunas de las reacciones de organizaciones y organismos internacionales que alertan sobre los peligros que representan los lazos entre crimen organizado y terrorismo, y proponen cambios en las estrategias para prevenirlos. Por último, para valorar la incidencia de las relaciones entre estos dos ANEV en espacios geográficos concretos, acudiremos a los resultados obtenidos en investigaciones con métodos cualitativos, que recogen datos de conexiones entre crimen organizado y grupos terroristas, especialmente en el contexto libio y la zona transahariana.

\section{SIMILITUDES Y DIFERENCIAS ENTRE GRUPOS DE CRIMINALES ORGANIZADOS Y GRUPOS TERRORISTAS}

5. Los grupos terroristas y los criminales organizados han aprovechado mejor los contextos de la violencia armada actual para desarrollar mayores capacidades y movilizar recursos e ideas a nivel internacional que el resto de los ANEV ${ }^{5}$. Supuestamente, uno de los escollos para analizar la evolución de la naturaleza de las relaciones de cooperación entre grupos de criminales y grupos terroristas es la falta de consenso a la hora de definir terrorismo y criminalidad organizada, la naturaleza de sus objetivos y actividades, y determinar cuándo adquieren una dimensión internacional, especialmente porque son dos fenómenos en constante evolución, que se presentan de manera multiforme ${ }^{6}$. Pero aproximaciones más prácticas a ambos fenómenos ponen el foco en las características de las organizaciones que desarrollan este tipo de actividades, lo cual resulta útil a la hora de identificar similitudes y diferencias entre los dos tipos de ANEV.

\footnotetext{
5 Linares Hamann, J. E., «Redes criminales transnacionales: Principal amenaza para la seguridad internacional en la posguerra fría», Revista Criminalidad, vol. 50, 2008, núm. 1, pp. 7-9.

${ }^{6}$ En la práctica, la definición de terrorismo puede ser extraída de fuentes distintas como la doctrina, los tratados existentes sobre distintos aspectos del terrorismo, decisiones judiciales y derecho derivado de organizaciones internacionales. El diccionario de Oxford registra una definición de terrorismo como el «uso de la violencia no oficial y no autorizado para la consecución de objetivos políticos» [STEvenson, A. (ed.), Oxford dictionary of English, Oxford, Oxford University Press, 2010]. Véanse los siguientes trabajos doctrinales dedicados a la definición de terrorismo: Cooper, H., «Terrorism: The Problem of Definition Revisited», American Behavioral Scientist, 2001, núm. 44, pp. 881-893; GIBBS, J., "Conceptualization of Terrorism», American Sociological Review, 1989, núm. 54, pp. 329-340; Hoffman, B., Inside Terrorism, Nueva York, Columbia University Press, 1998, y Ruby, Ch., "The definition of Terrorism», Analyses of Social Issues and Public Policy, 2002, núm. 2, pp. 9-14.
} 
6. En el caso del terrorismo, la mayor parte de los estudios se han caracterizado por adoptar como ejes centrales de sus análisis la necesidad de desarrollar un significado comúnmente aceptado del vocablo «terrorismo», concibiéndolo como un objetivo en sí mismo asociado con actores no estatales, y no como una estrategia o una práctica, descartando así que pueda ser parte de las agendas de seguridad de los gobiernos ${ }^{7}$. A partir de estas premisas, los dos grandes pilares de los programas de investigación consisten en identificar las causas del terrorismo y hallar las mejores estrategias y procedimientos para luchar contra él ${ }^{8}$.

7. El interés por definir el concepto de terrorismo se ha incrementado después de los atentados del 11 de septiembre, debido al nacimiento de grupos derivados, escindidos o auspiciados por la organización Al Qaeda, el auge del autodenominado Estado Islámico de Iraq y el Levante (EIIL) y la proliferación de grupos e individuos simpatizantes de este último, que afirman seguir su ideario y estar dispuestos a cometer actos de terrorismo en su nombre en distintas zonas geográficas. También se han multiplicado los recursos y esfuerzos para llevar a cabo análisis que expliquen este fenómeno, denominado terrorismo global, y así emprender el diseño de nuevas políticas anti-terroristas ${ }^{9}$. Este terrorismo global y, en concreto, el que desarrolla el EIIL, como señala Andrea Martini, desafía las fronteras establecidas por las potencias occidentales, pretende reconfigurar las relaciones hegemónicas a nivel mundial y desarrollar su proyecto político en los Estados en los que ha conseguido establecerse. Además, la doctrina subraya el carácter bárbaro y criminal del terrorismo global, acusándolo de irracional y enajenado y, en consecuencia, despolitizándolo, a pesar del desafío que representa para el sistema internacional y, también, para su tratamiento científico ${ }^{10}$. De ahí que, últimamente, los factores psicosociales que llevan al fanatismo y a la radicalización religiosa hayan presidido los análisis sobre el terrorismo yihadista, también denominado terrorismo global ${ }^{11}$. Por ello, las relaciones entre los

7 Stoнl, M., "Old Myths, New Fantasies and the Enduring Realities of Terrorism», Critical Studies on Terrorism, vol. 1, 2008, núm. 1, pp. 146-148, у Сномкку, N., «International terrorism: Image and reality», Crime and Social Justice, 1987, núms. 27/28, pp. 172-200.

${ }^{8}$ MeIsels, T., «The Trouble with Terror: The Apologetics of Terrorism. A Refutation», Terrorism and Political Violence, vol. 18, 2006, núm. 3, pp. 465-483.

9 Según el Global Terrorism Index de 2016, los grupos que se engloban en ese concepto de terrorismo global y que han sido los responsables del 74 por 100 de las muertes a causa de actos terroristas en 2015 son Al Qaeda, Boko Haram, los Talibanes y el Estado Islámico (Global Terrorism Index, Institute for Economic and Peace, 2016, pp. 49-60).

10 Martini, A., «El terrorismo global como amenaza al orden internacional. El caso del Estado Islámico», Relaciones Internacionales, núm. 32, 2016, pp. 79-95 (http://www.relacionesinternacionales. info/ojs/article/view/708.html). En este sentido se pronuncian autores como RougIER, B., «Le jihad en Afghanistan et l'emergence du salafisme-jihadisme», en RougIER, B. (dir.), Qu'est-ce que le salafisme?, París, Puf, 2008, pp. 65-86, y PAz, R., «Debates Within the Family: Jihadi-Salafi Debates on Strategy, Takfir, Extremism, Suicide Bombing, and the Sence of the Apocalypse», Salafism, Global. Islam's New Religious Movement, Nueva York, Columbia University Press, 2009, pp. 267-300.

11 Moyano, M. y Trujillo, H., Radicalización islamista y terrorismo, Claves psicosociales, Granada, Universidad de Granada, 2013, y de La Corte, L., Kruglanski, A., De Miguel, J., Sabucedo, J. M. y DíAZ, D., "Siete principios psicosociales para explicar el terrorismo», Psicothema, vol. 19, 2007, pp. 367-374. 
grupos de terroristas que practican este terrorismo global con el crimen organizado son el objeto principal de este estudio.

8. Entre los estudiosos pertenecientes a las escuelas mayoritarias, algunas de las corrientes realistas abogan por un tratamiento militar de esta amena$\mathrm{za}^{12}$, mientras que los institucionalistas liberales se inclinan por un tratamiento centrado en la cooperación y el Derecho internacional ${ }^{13}$, pero ambas escuelas otorgan al terrorismo una existencia objetiva sin dejar espacio para reflexionar sobre la evolución histórica de este fenómeno o el proceso social mediante el cual se ha construido su identidad y comportamiento, además de la amenaza que representa ${ }^{14}$. Sin embargo, el interés académico por desarrollar una definición de terrorismo no ha sido correspondido por los Estados, que sí han adoptado tratados para prohibir determinadas prácticas de terrorismo y luchar contra su financiación, pero sin llegar a una definición consensuada ${ }^{15}$. Incluso el calificativo de internacional también ha estado sujeto a diversas opiniones, aunque en la gran mayoría de los casos hace alusión a los objetivos y estrategias que diseñan los grupos terroristas con vocación internacional, y el carácter geográfico extensivo de sus estructuras organizativas y las distintas redes que desarrollan los actos de violencia bajo esa unidad jerárquica ${ }^{16}$.

9. El desacuerdo sobre qué tipo de violencia política puede llegar a denominarse terrorismo ha propiciado un programa de investigación específico dentro de los estudios críticos de seguridad, denominado estudios críticos sobre terrorismo, que contrarresta la visión de la corriente mayoritaria y ortodoxa de los estudios sobre terrorismo ${ }^{17}$. Según los estudios críticos sobre

12 ART, R. J. y RichaRdson, L., Democracy and Counterterrorism: Lessons from the Past, Washington, US Institute of Peace, 2007; GILPIN, R., "War Is Too Important to Be Left to Ideological Amateurs», International Relations, vol. 19, 2005, núm. 1, pp. 5-18; WALT, S., «Beyond Bin Laden: Reshaping US Foreign Policy», International Security, vol. 26, 2001-2002, pp. 56-78; STERN, J., "Obama and Terrorism», Foreign Affairs, vol. 94, 2015, núm. 5, pp. 62-78; GrAY, C. S., «Thinking Asymmetrically in times of terror», Parameters, vol. 32, 2002, núm. 1, pp. 5-14.

${ }^{13}$ NyE, J., "Get Smart: Combining Hard and Soft Power», Foreign Affairs, vol. 88, 2009, núm. 4, pp. 160-163, y «US Power and Strategy After Iraq», Foreign Affairs, vol. 82, 2003, núm. 4, pp. 60-66.

14 Dhanapala, J., «The United Nations' Response to 9/11», Terrorism and Political Violence, vol. 17, 2005, núms. 1/5, pp. 17-23, y PARKER, T., «Fighting an Antaean Enemy: How Democratic States Unintentionally Sustain the Terrorist Movement They Oppose», Terrorism and Political Violence, vol. 19, 2007, núm. 2, pp. 155-179.

15 Desde 1963, la comunidad internacional ha creado 19 instrumentos jurídicos internacionales para prevenir los actos terroristas, pueden consultarse en: http://www.un.org/es/counterterrorism/legalinstruments.html.

16 MaLIK, O., Enough of the Definition of Terrorism, Londres, The Royal Institute of International Affairs, 2000; Kennedy, R., «Is One Person's Terrorist Another's Freedom Fighter? Western and Islamic Approaches to "Just War"», Terrorism and Political Violence, vol. 11, 1999, núm. 1, pp. 1-21; y SoREL, J. M., "Some Questions about the Definition of Terrorism and the Fight against Its Financing», European Journal of International Law, vol. 14, 2003, núm. 2, pp. 365-378.

17 El hecho de que los mismos grupos armados hayan sido denominados como revolucionarios, liberadores o terroristas, como son los casos de Hamas (Gaza), Hezbollah (Líbano), Fuerzas Armadas Revolucionarias de Colombia, Partido de los Trabajadores Kurdos (Turquía) y los Tigres Tamiles (Sri Lanka) ha sido puesto de manifiesto por los estudios críticos de terrorismo. Ello obedece a que los análisis se han centrado en quienes protagonizan el terrorismo, los actores, pero sin tener en cuenta lo que se denomina el «comportamiento terrorista». Esta última perspectiva es mucho más aséptica y no entra a valorar la naturaleza y las convicciones de quienes comenten estos actos (LizARDo, O., "Defin- 
terrorismo, si se obvia que el terrorismo se enmarca en un cálculo racional de ganancias-beneficios derivado de una elección política, difícilmente puede afrontarse el análisis de las acciones terroristas que estratégicamente desarrollan los grupos de criminales organizados o los procesos de cooperación que acuerdan ambos ANEV ${ }^{18}$.

10. Por lo que respecta al crimen organizado, el acotamiento de este concepto y de otros como organización criminal, criminalidad organizada, delincuencia organizada o asociación ilícita no es tarea fácil y, tampoco, propensa a obtener un consenso internacional dada la versatilidad, heterogeneidad de los componentes de estos grupos y la pluralidad de sus actuaciones ${ }^{19}$. Por ello, la Convención de Palermo sobre Delincuencia Organizada Transnacional de 2000 solo pretendió definir el crimen organizado a través de parámetros identificadores, capaces de conseguir estándares legislativos entre los Estados firmantes, con la finalidad de reforzar la cooperación en la lucha contra este fenómeno ${ }^{20}$. Los Estados han tenido en cuenta estos criterios en sus legislaciones penales para poder castigar a estos grupos ${ }^{21}$. Casi siempre

ing and Theorizing Terrorism: A Global Actor-Centered Approach», Journal of World-Systems Research, vol. 14, 2015, núm. 2, pp. 91-118).

18 Freddman, L., "Terrorism as a Strategy», Government and Opposition, vol. 43, 2007, núm. 3, pp. 314-339; Burke, A., «The End of Terrorism Studies», Critical Studies on Terrorism, vol. 1, 2008, núm. 1, pp. 37-49; Воотн, K., «Critical Explorations», en Bоотн, K. (ed.), Critical Security Studies and World Politics, Londres, Lynne Rienner, 2005, pp. 1-18; GunnIng, J., «A Case for Critical Terrorism Studies?», Government and Opposition, vol. 42, 2007, núm. 3, pp. 363-393, y JACKson, R., "“Constructing Enemies": Islamic Terrorism in Political and Academic Discourse», Government and Opposition, vol. 42, 2007, núm. 3, pp. 394-426.

19 Por lo que respecta al concepto «crimen organizado», que proviene de la traducción literal de "organized crime», lo cierto es que sería más adecuado denominar a este fenómeno como «delincuencia organizada» siguiendo la versión al castellano de la Convención de Palermo y de otros actos existentes en la materia. Sin embargo, la denominación «crimen organizado» se ha extendido no solo en los medios de comunicación, también en el mundo académico y, además, las propias estructuras creadas por el Gobierno de España para la lucha contra este fenómeno también lo han acuñado, como son los casos del antiguo Centro de Inteligencia contra el Crimen Organizado (CICO) o el actual Centro de Inteligencia contra el Terrorismo y el Crimen Organizado (CITCO). Véase WoodiwIss, M., «Transnational Organized Crime: The Strange Career of an American Concept», en BEARE, M. (ed.), Transnational Organized Crime, Londres, Ashgate Publishers, 2013; RuIz Díaz, L., La lucha contra el crimen organizado en la Unión Europea, Tesis doctoral, Universidad de Granada, septiembre de 2015, p. 21 y pp. 22-57.

20 "Grupo estructurado de tres o más personas que exista durante cierto tiempo y actúe concertadamente con el propósito de cometer uno o más delitos graves» [La Convención de las Naciones Unidas contra la Delincuencia Organizada Transnacional y sus Protocolos, de 15 de noviembre de 2000, presentado como anexo a la Resolución de la Asamblea General 55/25 de la misma fecha (https:// www.unodc.org/pdf/cld/TOCebook-s.pdf)]. Esta definición fue también adoptada por la Decisión marco 2008/841/JAI, de 24 de octubre, DO L 300/42, de 11 de noviembre de 2008. EUROPOL calcula que al menos 5.000 organizaciones criminales están siendo investigadas en Europa, y ha establecido 11 criterios para poder identificar este tipo de organizaciones, que necesariamente tienen que cumplir los núms. 1, 3, 5 y 11: 1 . Colaboración entre más de dos personas; 2. Distribución de tareas; 3 . Actuación continuada o por tiempo prolongado; 4. Utilización de formas de disciplina y control interno; 5 . Sospecha de comisión de delitos graves; 6. Operatividad en el ámbito internacional; 7. Empleo de violencia u otras formas de intimidación; 8. Uso de estructuras de negocio o comerciales; 9. Actividades de blanqueo de capitales; 10. Ejercicio de influencia, y 11. Búsqueda de beneficio o poder (Doc. 6204/1/1997, ENFOPOL 35 rev DG).

${ }^{21}$ En el caso español, el art. 570 bis del Código Penal aporta una definición penal de organización delictiva como la formada por más de dos personas con carácter estable o por tiempo indefinido, que 
se trata de actos criminales de una naturaleza violenta grave, que se cometen para obtener un beneficio económico, sin mayores aspiraciones políticas, aunque necesiten corromper a funcionarios y a la clase política para que estos les faciliten la consecución de sus objetivos. Sus actividades las desarrollan individuos que obedecen las órdenes de una organización jerárquica cuya membresía, debido a la ilegalidad de las actividades que desarrolla, es restringida y fundamentalmente basada en la confianza étnica, familiar o geográfica ${ }^{22}$. Desde los años ochenta se ha identificado un nuevo tipo de criminalidad organizada, denominada transnacional, que explota las oportunidades que le ofrece la liberalización de los mercados y obtiene ventajas de las dificultades que existen para controlar las transacciones financieras en las que participa. Una criminalidad capaz de superar las restricciones geográficas y desarrollar lazos extra-nacionales con grupos similares, gracias a los avances en las tecnologías de la comunicación y la información. Además, han realizado cambios sus estructuras orgánicas, internacionalizándolas e incrementando su tamaño y el volumen de sus negocios, a través de nuevas rutas. En consecuencia, tienen mayores capacidades para retar a los Estados y operar a escala, y no necesitan grandes acumulaciones de poder y recursos ligados a un territorio, aunque sean capaces de emplazar a sus miembros en distintos territorios, aprovechando los flujos migratorios ${ }^{23}$.

11. Independientemente de las disensiones a la hora de definir terrorismo y crimen organizado, si tomamos como parámetro el comportamiento terrorista y el criminal podemos identificar los elementos que estos grupos tienen en común, y que han facilitado sus relaciones de cooperación a lo largo de la historia; relaciones que se han ido adaptando y transformando de acuerdo con la evolución del sistema internacional y los cambios en la naturaleza de sus actores. En los dos casos, nos encontramos con actores racionales capaces de identificar las ventajas de la cooperación para la comisión de actos criminales, que causan impacto tanto en las sociedades nacionales que las sufren, como en la sociedad internacional en su conjunto. No siguen indicaciones de ningún gobierno, ni actúan en beneficio de ellos, por lo que

de manera concertada y coordinada se repartan diversas tareas o funciones con el fin de cometer delitos (Ley Orgánica 10/1995, de 23 de noviembre, del Código Penal, BOE núm. 281, de 24 de noviembre de 1995, pp. 166-167. Última modificación: 28 de abril de 2015). Véase AuDA, G., «Le crime organisé, une perception variable, un concept polémique», Cahiers de la Securité, 2009, núm. 7, y LóPEZ MuÑOZ, J.: «El orden público bajo la amenaza de la criminalidad organizada», Revista de Derecho de la UNED, 2013, núm. 13, pp. 233-260.

22 Felsen, D. y Kalaitzidis, A., «A Historical Overview of Transnational Crime», en Reichel, P. (ed.), Handbook of Transnational Crime and Justice, Thousand Oaks, SAGE Publications, 2005, pp. 3-19, y Basiouni, C. y Vetere, E. (eds.), Organized Crime. A Compilation of U.N. Documents, 1975-1998, Nueva York, Transnational Publishers, Inc., 1998

23 ANDREAS, P. «Transnational Crime and Economic Globalization», en BERDAL, M. R. y SERRANO M. (eds.), Transnational Organized Crime and International Security: Business as Usual, Boulder, Lynne Rienner, 2002, pp. 37-52; CocKAYNe, J., Transnational Organized Crime: Multilateral Responses to a Rising Threat, International Peace Academy Publications, 2007; Ruggiero, V., «Transnational Crime: Official and Alternative Fears», International Journal of the Sociology of Law, vol. 28, 2000, núm. 3, pp. 187-199, y "Criminals and Service Providers: Cross-National Dirty Economies», Crime, Law and Social Change, vol. 28, 1997, núm. 1, pp. 27-38. 
la autonomía e independencia se convierten en sus atributos aunque, en ocasiones, hayan obtenido patrocinio de los Estados. Además, su uso de la violencia física o psicológica los sitúa al margen de los códigos éticos y legales, lo que condiciona sus relaciones con otros actores estatales y no estatales que actúan dentro de la legalidad ${ }^{24}$. Por ello muchos Estados han tipificado como delito tanto las actividades que desarrollan como la membresía en ambos grupos. Igualmente han sido objeto de tratados internacionales que combaten sus prácticas y también de decisiones de órganos de organizaciones internacionales que, en el caso del terrorismo, han llegado a identificar a grupos y a decretar sanciones contra sus miembros ${ }^{25}$. De cualquier manera, ambos grupos se adaptan bien a las nuevas circunstancias, tienen capacidad de innovación y representan una amenaza asimétrica compleja para los Estados. En ausencia de las autoridades del Estado pueden ofrecer servicios sociales a la población de los espacios geográficos en los que operan.

12. Thomas Sanderson identifica otro grupo de características de tipo operativo que también contribuyen a la cooperación de ambos ANEV. En primer lugar, necesitan una serie de recursos comunes, como identificaciones falsas, documentos de viajes, redes de transporte, capacidad de reacción y planes de supervivencia ${ }^{26}$. En segundo lugar, usan la violencia extrema o la amenaza de respuesta violenta, y las actividades criminales que más comparten son los secuestros, los asesinatos y la extorsión ${ }^{27}$. Por último, los miembros no suelen dejar estas organizaciones, y si lo hacen sufren represalias violentas, aunque, en los últimos estudios de casos, se ha demostrado el traspaso de individuos que actuaban en redes criminales pequeñas a grupos terroristas de ideario islamista y el incremento de la actividad criminal de los miembros de grupos relacionados con Al Qaeda en la zona del Sahel o el EIIL en Siria e Iraq ${ }^{28}$.

13. También existen diferencias entre ambos ANEV, lo que justifica que tanto Estados como organizaciones internacionales tradicionalmente los traten como amenazas separadas. Según Liz Campbell, el crimen organizado se analiza de manera estructural o sustantiva, al estar motivado por la acumulación de riqueza ${ }^{29}$. Estas organizaciones se comportan como empresas ilegales y aprovechan las rutas, contactos, recursos humanos e infraestructuras con las que cuentan para incrementar y diversificar el catálogo de productos con los que trafican y su cartera de clientes ${ }^{30}$. Sus relaciones con las auto-

\footnotetext{
24 Sanderson, T. M., "Transnational Terror and Organized Crime: Blurring the Lines», SAIS Review, vol. 24, 2004, núm. 1, pp. 53-54.

25 Entre otras, consúltense las Resoluciones 1267 (1999), 1989 (2011), 2161 (2014), 2170 (2014) y 2178 (2014) del Consejo de Seguridad de Naciones Unidas.

26 SANDERSON, T. M., op. cit., nota 24, pp. 52-54.

27 Ibid., pp. 49-61.

28 Dishman, Ch., «The Leaderless Nexus: When Crime and Terror Converge», Studies in Conflict and Terrorism, 2005, núm. 28, pp. 239 y ss.

29 Campbell, L., Organized Crime and Law, Oxford, Hart Publishing, 2013.

30 Williams, Ph., «Organizing Transnational Crime: Networks, Markets and Hierarchies», en WILLiams, Ph. y Vlassis, D. (eds.), Combating Transnational Crime: Concepts, Activities and Responses, Londres, Frank Cass, 2001, pp. 58 y ss.
} 
ridades se basan en evadirse de su control o controlarlas, y la corrupción de los funcionarios puede favorecer sus actividades criminales, pero ello no significa que intenten manejar el poder con una finalidad política ${ }^{31}$. Por el contrario, los grupos terroristas llevan a cabo actividades violentas por motivaciones ideológicas, políticas o religiosas, que pretenden generar miedo entre la población y causar daños, con el fin de cambiar las decisiones y acciones de los gobiernos ${ }^{32}$. Llegados a este punto, apoyándonos en los elementos comunes que presentan ambos fenómenos cabría preguntarse cuáles han sido los factores que están contribuyendo a activar procesos de colaboración entre grupos criminales y terroristas, y si estos factores han sufrido cambios en periodos recientes del sistema internacional, afectando a los modelos tradicionales de cooperación.

\section{FACTORES DE LA COOPERACIÓN ENTRE GRUPOS DE CRIMINALES ORGANIZADOS Y GRUPOS TERRORISTAS}

14. A través de los estudios de caso, la doctrina ha constatado que las relaciones entre grupos terroristas y criminales organizados han experimentado un salto en cuanto a su naturaleza e intensidad con respecto a épocas anteriores, cuando las características que ambos actores compartían ya propiciaban procesos de cooperación. En concreto, una vez revisada la doctrina más relevante sobre esta materia, podríamos identificar tres factores como los más determinantes a la hora de propiciar procesos de cooperación entre el crimen organizado y grupos terroristas: la financiación de los grupos terroristas en la actualidad, la dinámica de descentralización que presentan ambos actores y, por último, los contextos estatales de fragilidad en los que pueden actuar.

\subsection{La financiación de los grupos terroristas}

15. Aunque la necesidad de los grupos terroristas de financiarse siempre ha existido, en los últimos quince años se han producido una serie de circunstancias que han dificultado que tengan acceso al mismo volumen de recursos. Muchos estudios doctrinales coinciden en señalar la disminución del interés de los Estados por patrocinar a grupos terroristas desde el final de la Guerra Fría, lo que se ha traducido en un avance de la cooperación internacional en contra de la financiación del terrorismo ${ }^{33}$. Desde los atentados del $11 \mathrm{de}$

31 Campbell, L., "Organized Crime and National Security: A Dubious Connection?», New Criminal Law Review, vol. 17, 2014, núm. 2, pp. 220-251, p. 230.

32 Según Sergei Boeke, Al Qaeda en el Magreb, para conseguir la fundación de un califato en Mali, actuó en colaboración con los narcotraficantes de la región (BoEKE, S., "Al Qaeda in the Islamic Magreb: Terrorism, Insurgency, or Organized Crime?», Small Wars and Insurgency, vol. 27, 2016, núm. 5, pp. 914-936).

33 Hinojosa Martínez, L. M., La financiación del terrorismo y las Naciones Unidas, Madrid, Tecnos, 2008; Eldor, R. y Melnick, R., «Financial Markets and Terrorism», European Journal of Political 
septiembre de 2001, contabilizamos más de dieciséis años de aplicación de medidas decretadas en resoluciones del Consejo de Seguridad, nuevos estándares contra la financiación del terrorismo y el blanqueo de capitales a través de las legislaciones nacionales, y medidas adoptadas por organizaciones de carácter privado para contribuir al cumplimiento de las sanciones internacionales y legislaciones nacionales ${ }^{34}$. La cooperación internacional para frenar a los grupos terroristas de ideología islamista ha golpeado fuerte a las organizaciones no gubernamentales que pudieran compartir el mismo ideario y servir como intermediarios para alimentar su lucha, dificultando las donaciones privadas que nutren a los grupos terroristas, y controlando el origen y los destinatarios del Zakat, el 2,5 por 100 de los ingresos que los musulmanes deben dedicar a la beneficencia. También se han investigado las empresas tapadera utilizadas para blanquear el dinero de origen ilegal y las empresas que utilizan sus beneficios legales para financiar actos de terrorismo. De manera que la auto-financiación se ha convertido necesariamente en la alternativa para estos grupos ${ }^{35}$.

16. Estas circunstancias han llevado a muchos individuos afiliados a organizaciones terroristas a utilizar su propio patrimonio, recursos financieros, salarios, prestaciones sociales o, incluso, créditos para financiar las actividades de las células a las que pertenecen. Los últimos estudios de casos publicados sobre la financiación de pequeñas células yihadistas establecidas en Europa, que planeaban cometer ataques a pequeñas escala, ponen de manifiesto que sus recursos eran escasos y fundamentalmente procedentes de ahorros y salarios de sus miembros, además de lo obtenido en actividades delictivas. El chantaje, la delincuencia común, el fraude de tarjetas de crédito o las pequeñas transacciones de estupefacientes ahora constituyen métodos de financiación de las de pequeñas células terroristas. Sin ir más lejos, el tráfico de drogas fue el principal mecanismo para conseguir los explosivos

Economy, vol. 20, 2004, núm. 2, pp. 367-386; y Masciandaro, D. (ed.), Global Financial Crime: Terrorism, Money Laundering, and Off Shore Centres, Londres, Ashgate Publishing, 2004.

${ }_{34}$ Véase la Resolución 1373 del Consejo de Seguridad adoptada diecisiete días después de los atentados del 11 de septiembre, el 28 de septiembre de 2001, S/RES/1373(2001) y Financial Action Task Force (FATF), Terrorist Financing, 29 de febrero de 2008 (http://www.fatfgafi.org/medialfatf/documents/ reports/FATF\%20Terrorist\%20Financing\%20Typologies\%20Report.pdf), FATF, Global Money Laundering and Terrorist Financing Threat Assessment, julio de 2010 (http://www.fatf-gafi.org/publications/ methodsandtrends/documents/globalmoneylaunderingterroristfinancingthreatassessment.html) y el FATF, Financing The Terrorist Organization Islamic State in Iraq and The Levant, 17 febrero de 2015 (http:// www.fatf-gafi.org/media/fatf/documents/reports/Financing-of-the-terrorist-organisation-ISIL.pdf). El 10 de abril de 2002 entró en vigor el Convenio Internacional para la Represión de la Financiación del Terrorismo, aprobado por la Asamblea General de Naciones Unidas en su Resolución A/RES/54/109, de 9 de diciembre de 1999, y abierto a la firma el 10 de enero de 2000.

35 El FATF, en octubre de 2005, publicó un informe donde se exploraron los mecanismos de financiación de 22 células terroristas y las actividades financieras de los individuos que formaban parte de las mismas. El estudio puso de manifiesto que la lucha internacional y estatal contra la financiación del terrorismo había llegado a afectar tanto a grupos pequeños/células como a la cúpula de las organizaciones, por lo que la autofinanciación se había convertido en una alternativa por la que los miembros suman pequeños recursos financieros, de manera legal o ilegal, para mantener a la organización (FATF, Emerging Terrorist Financing Risk, Paris, FATF, 2015, http://www.fatf-gafi.org/publications/methodsandtrends/documents/emerging-terrorist-financing-risk.html). 
en los atentados del 11 de marzo en Madrid, y la mayoría de los ataques cometidos en Europa no superaron los 10.000 euros de coste total ${ }^{36}$. Pero ese tipo de delitos no siempre son suficientes para financiar grandes actividades, ni para mantener una estructura organizativa, por lo que las grandes fuentes de financiación privadas de los grupos terroristas provienen de actividades delictivas de carácter criminal, que pueden desarrollarse en colaboración con criminales organizados.

17. Por tanto, uno de los principales condicionantes de las relaciones entre grupos terroristas y criminales organizados es sin duda la necesidad de financiación de los primeros y las posibilidades que les ofrecen los segundos para obtenerla a cambio de otros beneficios, como son valerse de los conocimientos en estrategias de terrorismo y de la influencia de grupos terroristas sobre la población y facciones políticas y armadas para proteger sus negocios y aumentar sus beneficios. La cooperación entre ambos actores tiene algunos ejemplos a lo largo de la historia, como los documentados lazos entre ETA o el IRA con guerrillas de países de América Latina involucradas en el narcotráfico, como las FARC. En este caso, un grupo insurgente dedicado al narcotráfico cambió recursos financieros por los conocimientos en la lucha armada de un grupo terrorista ${ }^{37}$.

18. En el caso del llamado terrorismo global, los objetivos políticos-ideológicos afectan a nivel local, regional e internacional, y eso es lo que marca diferencias con respecto a esquemas de cooperación anteriores ${ }^{38}$. Hoy, organizaciones terroristas con una estricta jerarquía del poder concentrada en una cúpula responsable de los mecanismos de reclutamiento, entrenamiento y objetivos necesitarían encontrar mecanismos de financiación más sofisti$\operatorname{cados}^{39}$. Pero las organizaciones terroristas derivadas, afiliadas o dependientes de una organización mayor pueden acceder más fácilmente a fuentes de financiación, legales o no legales, dependiendo de su estructura, objetivos y actividades y, sobre todo, del contexto en el que actúan ${ }^{40}$. Así, el núcleo duro de la organización solo sigue ejerciendo el control ideológico, mientras las

36 Emilie Oftedal llevó a cabo una minuciosa investigación para la que utilizó los datos de las investigaciones de las células yihadistas desmanteladas en Europa para identificar el origen de sus recursos financieros y los costes de sus actividades (OFTEDAL, E., The Financing of Jihadist Terrorist Cells in Europe, Forsvarets Forskningsinstitutt, Norwegian Defence Establishmenet, FFI-rapport 2014/02234, 6 de enero de 2015, http://www.ffi.no/no/Rapporter/14-02234.pdf).

37 La inteligencia británica afirmó que las FARC habían pagado al IRA más de dos millones de dólares en concepto de entrenamiento militar, manejo de armas y explosivos y técnicas de combate. Otras informaciones de las autoridades italianas apuntan a lazos entre ETA y la Camorra. Esta última surtía de armas pesadas a la organización terrorista a cambio de cocaína y hachís, que previamente la organización había podido conseguir moviendo armas ilegales en América Latina (CURTIS, G. E. y KARACAN, T., The Nexus Among Terrorists, Narcotics Traffikers, Weapons Proliferators, and Organized Crime Networks in Western Europe, Federal Research Division, Library of Congress, 2002, https://www.loc.gov/ $\mathrm{rr} / \mathrm{frd} / \mathrm{pdf}$-files/WestEurope_NEXUS.pdf).

38 Byrne, E., «Nexus of Terror», Intersec, vol. 10, 2009, núm. 4, pp. 10-12.

39 GimÉnEZ-SALINAS Framis, A., "Las finanzas del terrorismo de al-Qaida: una lucha desenfocada», Athena Intelligence Journal, vol. 2, 2007, núm. 22, pp. 195-212.

40 Dishman, Ch., op. cit., nota 28, pp. 243-246. 
células locales deciden sobre su propia logística y actos y, además, se responsabilizan de su propia financiación ${ }^{41}$.

19. Los casos de colaboración criminal más importantes ocurren cuando los grupos terroristas deciden garantizar sus objetivos políticos a través de la ampliación de sus recursos y participan en actividades criminales a gran escala como la red de narcotráfico de derivados del opio en el caso de los Talibanes, el tráfico de combustible por el EIIL o el tráfico de tabaco o los secuestros por parte de Al Qaeda en el Magreb Islámico (AQMI) como se examinará más adelante ${ }^{42}$. A cambio los criminales obtienen seguridad durante el traslado de los bienes con los que trafican y el acceso a las rutas controladas por grupos terroristas y facciones afines. En ese sentido, Chris Dishman ha desarrollado un estudio en el que pone de manifiesto el desarrollo de la red de Hezbollah, que combina una estructura rígida y jerárquica, para evitar infiltraciones de enemigos, con la flexibilidad adecuada para captar el máximo número de miembros, simpatizantes y financiación en los Estados en los que posee presencia ${ }^{43}$.

20. En definitiva, ante la pérdida del apoyo económico público y el avance del Derecho internacional y las legislaciones nacionales para hacer frente al terrorismo y su financiación, las organizaciones terroristas han buscado financiación de carácter privado, mayormente procedente de actos delictivos. La privatización de los recursos de los grupos terroristas necesita de una dinámica descentralizadora, determinante para la intensificación y transformación de la cooperación con la criminalidad organizada.

\subsection{La descentralización de las organizaciones terroristas y los grupos de criminales organizados}

21. Los cambios en la naturaleza y en el alcance de los dos procesos básicos que tienen lugar en el sistema internacional, la cooperación y el conflicto, han sido determinantes para la evolución de la funcionalidad, autonomía, objetivos y recursos de los actores de las relaciones internacionales, incluidos los ANEV. Las actividades de los grupos terroristas y grupos de criminales organizados, hasta la década de los ochenta, tenían unos efectos transfronterizos limitados, pero han podido intensificarse gracias a la liberalización del comercio, el libre movimiento de capitales, los avances tecnológicos en materia de comunicación y transmisión de la información, los desplazamientos masivos de poblaciones y el incremento de las desigualdades, como también ha ocurrido con las actividades de otros actores, legales, ya sean públicos o privados ${ }^{44}$.

41 Giménez-Salinas Framis, A., op. cit., nota 39, p. 196.

42 Doward, J., «How Cigarettes Smuggling fuels Africa's Islamic Violence», The Guardian, 27 de enero de 2013, y Wannenburg, G., "Links Between Organized Crime and Al Qaeda», South African Journal of International Affairs, vol. 10, 2003, núm. 2, pp. 77-90.

43 Dishman, Ch., op. cit., nota 28, pp. 237-252.

44 Jaime-Jiménez, O. y CAStro Moral, L., «La criminalidad organizada en la Unión Europea», Revista CIDOB d'Afers Internacionals, 2010, núm. 91, pp. 173-194, pp. 174-175. 
Un ejemplo de ello es el incremento de la actividad criminal en Europa del este desde el final de la Guerra Fría. Gracias a la desregulación de los mercados y los procesos de privatización que han experimentado los Estados de esa región, las redes de criminales han adquirido nuevas oportunidades para expandirse y comercializar con sus "productos» en un mayor número de regiones del planeta ${ }^{45}$. Para Sansó-Rubert, la globalización en su vertiente económica, junto con el vacío represivo de algunos contextos estatales representa una variable trascendental para explicar la proliferación de las organizaciones de criminales ${ }^{46}$.

22. El proceso de globalización ha difuminado las distancias geográficas, y permitido que las organizaciones criminales y terroristas tengan mayores oportunidades para poder acceder e intercambiar información, mejorar sus comunicaciones y movilizar sus recursos ${ }^{47}$. En consecuencia, han podido abandonar las estructuras jerárquicas rígidas que caracterizaban a muchas organizaciones, procediendo a una descentralización a través de redes y de nodos, coloquialmente calificados como «franquicias», que facilitan el contacto con otros actores ${ }^{48}$. Los grupos terroristas han desarrollado la misma lógica que las empresas multinacionales, transformando sus estructuras jerárquicas en redes, dotando a la organización de mayor flexibilidad y capacidad de adaptación a los espacios locales, a pesar de que se mantenga un control fundamentalmente ideológico por parte de la cúpula. Esta circunstancia ha sido beneficiosa para los grupos criminales, que extraen ventajas de las actividades de los grupos terroristas a la hora de desestabilizar las estructuras políticas de los distintos Estados en los que operan, minando las capacidades de sus fuerzas de seguridad ${ }^{49}$. Por tanto, las estructuras terroristas basadas en el centralismo autoritario han dado paso a la creación de células más o menos coordinadas alrededor de las cuales se establecen una serie de lazos débiles con la estructura central ${ }^{50}$. Las actividades de las dis-

45 CARTER, D. L., «International Organized Crime. Emerging Trends in Entrepreneurial Crime», en Ryan, P. J. y Rush, G. (eds.), Understanding Organized Crime in Global Perspective: a Reader, Thousand Oaks, Sage Publications, 1995, pp. 135 y ss.

46 SANSó-Rubert Pascual, D., "Criminalidad organizada y tráfico ilícito de armas ligeras. Repercusiones en el ámbito de la seguridad internacional», Cuadernos de Estrategia, 2011, núm. 152, pp. 182-183.

47 Según Manuel Castells: «La globalización no es fenómeno de internacionalización. En sentido estricto es el proceso resultante de la capacidad de ciertas actividades de funcionar como unidad en tiempo real a escala planetaria. Es un fenómeno nuevo porque solo en las dos últimas décadas del siglo Xx se ha constituido un sistema tecnológico de sistemas de información, telecomunicación y transporte, que ha articulado todo el planeta en una red de flujos, en las que confluyen las funciones y unidades estratégicamente dominantes de todos los ámbitos de la actividad humana» (CASTELLS, M., «Globalización, Estado y sociedad civil: el nuevo contexto histórico de los derechos humanos», ISEGORIA, 2000, núm. 22, pp. 6-7).

48 Castells, M. (ed.), La sociedad red: una visión global, Madrid, Alianza Editorial, 2006.

49 Jamieson, A., «Transnational Organized Crime: A European Perspective», Studies in Conflict and Terrorism, vol. 24, 2001, núm. 5, pp. 377-387, p. 394; EvANs, R., «Organized Crime and Terrorist Financing in Northern Ireland», Jane's Intelligence Review, 2002, y «Basque Fatherland and Liberty, Euskadi Ta Askatasuna (ETA)», FA Intelligence Resource Program, 2002 (http://www.cfr.org/separatist-terrorism/ basque-fatherland-liberty-eta-spain-separatists-euskadi-ta-askatasuna/p9271).

50 ReInARES, F., Terrorismo Global, Madrid, Taurus, 2003, pp. 90 y ss., y MARTINI, A., op. cit., nota 10, pp. 79-95 
tintas células se reconocen porque se establecen dentro de una misma lógica y programa ideológico que les otorga una identidad propia ${ }^{51}$. De hecho, los ataques perpetrados por pequeños grupos parecen obedecer a la estrategia de la organización, a pesar de que se traten de actos aislados desarrollados, incluso, por individuos solitarios ${ }^{52}$.

23. Las características clásicas del crimen organizado han sido la especialización, la jerarquía y los negocios ilegales ${ }^{53}$. Pero, en los últimos tiempos, han proliferado los pequeños negocios, el llamado "crimen desorganizado», producto de acuerdos breves y esporádicos entre pequeños grupos o alianzas efímeras derivadas de la pérdida de jerarquía. Estas estructuras descentralizadas, con múltiples líderes, toman decisiones y desarrollan operaciones con mayor autonomía; pero siguen conviviendo con organizaciones tradicionales de grandes dimensiones y conexiones internacionales (Camorra o la mafia siciliana) u organizaciones formadas por individuos vinculados por su origen nacional (mafias china, albanesa, rumana, etc. ${ }^{54}$. En las estructuras horizontales de criminales, los líderes no tienen autoridad sobre el conjunto de la organización, pero sí son capaces de establecer lazos a nivel internacional, cooperando o haciendo alianzas con otros actores violentos que se encuentran en distintas regiones del planeta, adquiriendo la denominación de crimen global o de la globalización del crimen organizado ${ }^{55}$.

24. Los criminales organizados, independientemente de su estructura, llevan a cabo actividades ilegales como el robo, fraude, asesinatos contratados, el tráfico de armas, drogas, productos de lujo o seres humanos, pero no buscan apoderarse del Estado, declarar la guerra al Estado o derrocar al gobierno ${ }^{56}$. Sin embargo, para mantener sus actividades y mejorar sus beneficios, normalmente intentan influenciar a las instituciones de gobierno, y para ello las alianzas con grupos terroristas resultan más fáciles y ventajosas. En

51 McDonald, K., Our Violent World. Terrorism in Society, Londres, Palgrave Macmillan, 2013, pp. $168-180$.

52 Weimann, G., «Lone Wolves in Cyberspace», Journal of Terrorism Research, vol. 3, 2012, núm. 2, pp. 91-100, y PANTuccI, R., A Typology of Lone Wolves: Preliminary Analysis of Lone Islamist Terrorists, Londres, International Centre for the Study of Radicalisation and Political Violence, 2011.

53 Varese, F., Organized Crime: Critical Concepts in Criminology, Londres, Routledge, 2010.

54 Alison Jamieson analiza la cooperación entre distintos grupos de criminales organizados a nivel mundial, identificando una clara evolución en estas relaciones, especialmente a medida que estos grupos se insertan en la dinámica de la globalización. En su análisis identifica colaboraciones entre grupos de criminales que pertenecen a la misma etnia pero que operan en países distintos, como las comunidades chinas de los cinco continentes. Otro modelo más avanzado es el modelo de grupo étnico comprador y grupo étnico vendedor como son las relaciones entre los cárteles de Colombia o México con asociaciones mafiosas de los países en los que se vende la droga. Estos acuerdos pueden ser puntuales o permanentes (JAmIESon, A., Cooperation Between Organized Crime Groups Around the World, Viena, Jahrbuch für internationale Sicherheitspolitk, Bureau for Military Scientific Studies, Federal Ministry of Defense, 1998).

55 Linares Hamann, J. E., «Redes criminales transnacionales: Principal amenaza para la seguridad internacional en la posguerra fría», Revista Criminalidad, vol. 50, 2008, núm. 1, pp. 1-9.

56 Es cierto que en el contexto concreto de los narco-Estados de América Latina, como Colombia o Guatemala, los criminales organizados en determinados momentos han llegado a declarar la guerra al Estado para poder conseguir sus objetivos, forzando a las autoridades a adoptar decisiones que les dotaban de mayor impunidad. 
definitiva, la descentralización les ha proporcionado mayor flexibilidad a la hora de buscar sus aliados y diseñar sus relaciones de cooperación, pudiendo así abarcar mayor número de espacios y conseguir más beneficios. La descentralización no impide que sus actividades ilegales y violentas sigan teniendo un impacto global, a la vez que reduce los costes y los riesgos que conllevan las actuaciones por parte de estructuras organizativas grandes, que suelen atraer la atención internacional y ser objeto de medidas sancionadoras.

\subsection{Estados frágiles y cambios en la conflictividad armada}

25. Los cambios en la dinámica global de conflictos, consecuencia de la reducción drástica de las guerras interestatales y el incremento paralelo de los conflictos armados internos ha dejado a los Estados sin el monopolio del uso masivo de la violencia ${ }^{57}$. Este vacío ha propiciado la participación de nuevos actores, incluidos los ANEV ${ }^{58}$. Especialmente, son las organizaciones de criminales y los grupos terroristas los que han ganado mayores espacios en contextos de desigualdades socio-económicas y políticas, gestionados por gobiernos incapaces de garantizar derechos, servicios públicos y seguridad ${ }^{59}$.

26. En efecto, Estados frágiles que presentan serios déficit en materia de gobernanza, legitimidad y control de sus fronteras constituyen un espacio privilegiado para el desarrollo de las relaciones entre ANEV ${ }^{60}$. Los niveles de fragilidad de los Estados pueden variar. Podemos encontrarnos con situaciones de debilidad de las instituciones, pero que todavía son capaces de desarrollar las funciones de seguridad del Estado, aunque no proveen de los servicios necesarios a la población, lo que desemboca en una crisis de legitimidad. En este caso, el crimen organizado suele llegar a tener acceso a una economía legítima, incluso al aparato político, generando una situación de simbiosis, especialmente en contextos de desregulación económica, donde las élites políticas y económicas empiezan a actuar de manera ilegal y los grupos disidentes llegan a utilizar la violencia cometiendo actos de terrorismo

57 Treverton, G. F., Matthies, C., Cunningham, K. J., Goulka, J., Ridgeway, G. y Wong, A., Film Piracy, Organized Crime and Terrorism, Santa Mónica, RAND Coorporation, 2009.

58 Josep Ibáñez y Constanza Sánchez han desarrollado un profundo análisis sobre la transformación de los patrones de conflictividad armada y la expansión de la criminalidad transnacional organizada, en el que también se señala a la globalización como factor explicativo de auge de este actor no estatal violento, y propone una serie de categorías que explican el grado de relación e influencia mutua entre conflictividad armada y crimen organizado, que después se ilustran con estudios de caso [IBÁÑEZ Muñoz, J. y SÁnchez Avilés, C. (dirs.), Mercados ilegales y violencia armada, Madrid, Tecnos, 2015].

59 FerreIRA, O. R., «Violent Mexico: Participatory and Multipolar Violence Associated with Organized Crime», International Journal of Conflict and Violence, vol. 10, 2016, núm. 1, pp. 40-60; MAZZITELLI, A. L., "Transnational Organized Crime in West Africa: The Additional Challege», International Affairs, vol. 83, 2007, núm. 6, pp. 1071-1090, y WANG, P., «The Rise of the Red Mafia in China: A case Study of Organized Crime and Corruption in Chogqing», Trends in Organized Crime, vol. 16, 2013, núm. 1, pp. 49-73.

60 Buzan, B., People, States and Fear, Boulder, Lynne Rienner, 2008, pp. 83-89, y Casanova, O., «Los Estados fracasados», en García SEgura, C. y Rodrigo, A. (eds.), La seguridad compartida. Nuevos desafíos, amenazas y conflictos armados, Madrid, Tecnos, 2008, pp. 83-89. 
reivindicando un determinado cambio en el modelo de Estado y de gobierno ${ }^{61}$. Pero, podemos encontrarnos con Estados frágiles incapaces de garantizar la seguridad de la población, desprovistos del monopolio de la fuerza y el control de los recursos, al menos en parte del territorio, por lo que otros actores asumen esas funciones, especialmente ANEV. Las situaciones más extremas son las que padecen los Estados completamente fallidos o en descomposición, en los que el gobierno carece de recursos, capacidades, poder y ha dejado de ejercer sus competencias soberanas sobre población y territorio ${ }^{62}$.

27. En los Estados fallidos, en los últimos años, se han detectado mayor intensidad y variedad de relaciones entre grupos de criminales organizados y grupos de terroristas, especialmente después de luchas internas sangrientas e invasiones sucedidas de actores insurgentes que utilizan estrategias terroristas $^{63}$. En estos contextos, los grupos terroristas intentan convertirse en fuerzas integradas de las nuevas estructuras de gobierno, y la criminalidad organizada desea que las estructuras de gobierno que se diseñen les permitan mantener y mejorar sus actividades ${ }^{64}$.

28. Por tanto, nos encontramos en una nueva etapa de cooperación, especialmente ligada a las situaciones de conflicto interno y de post-conflicto en Estados frágiles, en los que grupos terroristas y criminales no tienen estrategias a gran escala ni a largo plazo, pero sí necesitan la continuidad de la fragilidad del Estado y la prolongación de la violencia para garantizar su cooperación y perseguir beneficios mutuos en un contexto de impunidad. Desde ese momento, desorden y violencia dentro de las fronteras son sus mejores aliados ${ }^{65}$. Las actividades de grupos criminales proveen a los terroristas de armas y dinero para pagar a sus combatientes ${ }^{66}$. Mientras que los grupos terroristas de ideología islamista violenta pretenden cambios en el statu quo de la organización política y en las normas que organizan la vida social, económica, cultural y familiar de la población, la criminalidad organizada, en

61 En el caso de la violencia política, entendida por Cesare Beccaria y Jeremy Bentham como una fractura en el contrato social que une a los ciudadanos y a las autoridades, normalmente el surgimiento está relacionado con Estados en los que han existido fuertes dosis de violencia institucional (tortura, penas de muertes, asesinatos y otras formas de desarrollo de la violencia), como ocurría en el régimen de Gadafi, normalmente provoca violencia política por parte de actores no estatales (BEccarIA, C., Dei delitti e delle pene, Turín, UTET, 1965, y Bentham, J. A., Fragment of Government. With an Introduction to the Principles of Morals and Legislation, Basil, Blackwell, 1967).

62 Di JoHn, J., "Conceptualizing the Causes and Consequences of Failed States: A Critical Review of the Literature», Revista de Estudios Sociales, 2010, núm. 37, pp. 46-86.

${ }_{63}$ Por ejemplo, se calcula que un tercio de los miembros del EIIL pertenecían a la inteligencia y a los servicios secretos de Sadam Husein y han respondido de esa manera a la invasión de su país. De hecho, el EIIL ha promovido docenas de motines carcelarios y liberado a miles de veteranos de guerras y militares que se han unido a sus filas (Lynch, M., The New Arab Wars: Uprising and Anarchy in the Midle East, Nueva York, Public Affairs, 2015, y Gerges, F. A., ISIS: A History, Princenton, Princenton University Press, 2015).

64 Schnekener, U., op. cit., nota 1, pp. 29-37.

65 Shelley, L., "The Unholy Trinity: Transnational Crime, Corruption, and Terrorism», The Brown Journal of World Affairs, vol. 11, 2005, núm. 2, pp. 101-111.

${ }_{66}$ También la mafia italiana y la japonesa se beneficiaron enormemente de las situaciones de postconflictos en sus respectivos países después de la Segunda Guerra Mundial (ibid., p. 104). 
principio, no tiene aspiraciones territoriales ni de gobierno, y sí pretende defender sus propios intereses e instigar a las autoridades para que mantengan la situación que asegure y consolide su posición.

29. Otros casos bien distintos, como los que señala Esteban Arratia, son los de algunos Estados de Latinoamérica, donde los criminales organizados han pasado de ser empresarios violentos concentrados en la competencia por mercados ilícitos a una especie de «insurgencia criminal», cuyo principal objetivo consiste en ganar autonomía mediante el ahuecamiento o vaciamiento del Estado y la creación de enclaves criminales para asegurar amplios márgenes de maniobra en el desarrollo de sus actividades ilícitas, y no necesitan alianzas con grupos terroristas porque ellos mismos son capaces de desarrollar estrategias de terror ${ }^{67}$. Además, están dispuestos a enfrentarse con los gobiernos si resulta necesario y han desarrollado verdaderos ejércitos capaces de hacer frente a las fuerzas militares gubernamentales. Llegan a moldear una nueva relación con la ciudadanía, derivada de una disminución de la legitimidad, funcionalidad y credibilidad del gobierno. En algunos casos, la insurgencia criminal es capaz de proveer a los ciudadanos de los servicios y la seguridad que no les proporcionaba el Estado, estableciendo un «Estado embrión del terror», con una nueva estructura económica en torno al conflicto y una relación con la población basada en el miedo y el agradecimiento, lo que le permite llevar a cabo sus actividades delictivas con un menor rechazo ${ }^{68}$. Así, estos grupos acumulan un importante capital político que les brinda la oportunidad de competir con la autoridad estatal ${ }^{69}$.

30. En definitiva, frente a la lucha emprendida por Estados y organizaciones internacionales contra el terrorismo y el crimen organizado, la globalización económica y tecnológica ofrece a estos grupos oportunidades para obtener alternativas de financiación, transformar sus estructuras jerárquicas en fórmulas más descentralizadas y flexibles, que les permitan abarcar mayores espacios, incrementar sus actividades y capacidades de alcanzar sus objetivos. Ello, unido a las posibilidades que les brindan los llamados Estados frágiles o fallidos, les permite ocupar espacios de poder sobre el territorio y la población donde los gobiernos y sus instituciones han dejado de ejercerlos o, incluso, han desaparecido. También propician un nuevo contexto para el nacimiento de un entramado de relaciones que profundizan en las que hasta la fecha han sido estudiadas. Por tanto, los Estados con una situación de fra-

67 ARratia SANDOVAL, E., "¿Insurgencia criminal? La cambiante naturaleza del crimen organizado transnacional en México y Centroamérica», Estudios de Seguridad y Defensa, 2015, núm. 5, pp. 39-76, p. 42.

68 Sobre el nacimiento del «Estado embrión del terror» en contexto de guerra y violencia estructural, véase NAPOLEONI, L., "El nacimiento del Estado embrión del terror», en Yihad. Cómo se financia el terrorismo en la nueva economía, Barcelona, Tendencias, 2004, pp. 129-152. Este ha sido el caso de los cárteles en algunas zonas de México, véase BunKer, R., «Introduction: The Mexican Cartels-Organizad Crime vs. Criminal Insurgency», Trends in Organized Crime, vol. 16, 2013, núm. 2, pp. 131 y ss.

${ }^{69}$ Así lo ponía de manifiesto el secretario general de Naciones Unidas en su Informe sobre la Misión de Apoyo a las Naciones Unidas en Libia de 16 de mayo de 2016, cuando se refería a los reglamentos, el pago de impuestos y el programa educativo religioso en las zonas de Sirte y Sabri (S/2016/452, pp. 5-9). 
gilidad, ya sean Estados inestables, débiles, fallidos o en descomposición, no solo suponen un peligro para su gobernanza interna, también lo son para la gobernanza regional y global ${ }^{70}$.

\section{MODELOS DE COOPERACIÓN ENTRE CRIMEN ORGANIZADO Y GRUPOS TERRORISTAS}

31. El terrorismo y la delincuencia organizada transnacional, según puso de manifiesto el secretario general de Naciones Unidas, son fenómenos distintos en cuanto a su forma de actuar y objetivos pero, en los últimos quince años, se vienen detectando cada vez más interacciones entre ambos que afectan a la paz y a la seguridad internacionales ${ }^{71}$. La obtención de información sobre la cooperación entre el crimen organizado y grupos terroristas es difícil, y son escasos los ejemplos que pueden documentarla. Además, no en todos los contextos geográficos se constatan relaciones entre grupos terroristas y organizaciones de criminales organizados, bien porque alguno o ninguno de estos dos fenómenos tiene una incidencia significativa o porque, simplemente, alguno de estos grupos no actúa con alcance internacional, y por tanto, no pueden identificarse modelos de relación claros.

32. El concepto de conexión (nexus) entre terrorismo y crimen organizado recobra fuerza a principios de los años noventa, después de la desmembración de la Unión Soviética, la entrada de China en la economía de mercado y la multiplicación de Estados frágiles y los ANEV adaptasen su modus operandi al nuevo contexto geopolítico. Los primeros tipos de colaboración documentados tenían una naturaleza logística y consistían en intercambios puntuales de bienes, como drogas, dinero, armas, explosivos o instrucción según las necesidades de ambas organizaciones. Pero, la posguerra fría ha llevado a los grupos criminales y terroristas a cambiar muchos de sus enfoques operativos y, en ocasiones, más que una cooperación se han identificado actuaciones de imitación y convergencia por razones tácticas. Organizaciones criminales han utilizado técnicas de insurgencia/terrorista como herramienta operativa mientras que los terroristas/insurgentes llevaban a cabo actuaciones criminales para financiar su causa. Un ejemplo de ello es el de los criminales que intimidan a las sociedades y a los ciudadanos a través del terror para conseguir fines políticos, como el asesinato del Juez Giovanni Falcone por la mafia italiana en los noventa, o los actos de terrorismo cometidos por narcotraficantes colombianos, como los del grupo dirigido por $\mathrm{Pa}$ blo Escobar ${ }^{72}$. En la región de los Balcanes, los grupos criminales se hicieron fuertes a raíz de las relaciones que entablaron con las facciones durante el conflicto armado, generando una economía de guerra que continuó después

\footnotetext{
70 SChNecKener, U., op. cit., nota 1, p. 23.

71 Informe del Secretario General sobre la amenaza de los terroristas que se benefician de la delincuencia organizada transnacional, de 21 de mayo de 2015 (S/2915/336), p. 1.

72 SANDERSON, Th., op. cit., nota 26, pp. 49-61.
} 
del proceso de paz ${ }^{73}$. Los esfuerzos por terminar con esas relaciones dieron lugar a ataques terroristas contra las instituciones y sus representantes, como el atentado contra el antiguo Primer Ministro serbio Zoran Djindijc ${ }^{74}$.

33. Ahora bien, algunos grupos terroristas han comenzado colaborando con organizaciones criminales por razones logísticas y, posteriormente, han intercambiado sus tácticas por necesidades financieras o afán de lucro, escondidas entre objetivos y retórica política, permitiéndoles así desarrollar actividades delictivas sin perder el apoyo de simpatizantes y seguidores. Y, en situaciones de conflicto prolongado, abandonan su agenda política para convertirse en criminales de manera más constante y recurrente, reemplazando su motivación político-religiosa por una motivación económica. El líder de AQMI, Mokhtar Bellmokhtar, se ha ganado el apodo «el Marlboro» por su intensa participación en el tráfico de cigarrillos en la región. Al-Nusra, en Siria, ha focalizado buena parte de sus energías en actividades delictivas, a costa del capital político acumulado en la defensa de su causa. Y el grupo yihadista filipino Abu Sayyaf, fiel al EIIL, ha pasado fundamentalmente a lucrarse de actividades criminales ${ }^{75}$. De la misma manera, los grupos de criminales organizados, por razones logísticas acuerdan intercambiar bienes o servicios con grupos de terroristas y, también, han utilizado tácticas de terrorismo cuando han querido intimidar al gobierno o la población para seguir manteniendo sus beneficios.

34. La evolución del crimen organizado y la insurgencia terrorista ha intensificado los tipos de relaciones que puede llegar a establecerse entre ambos grupos, a pesar de que la insurgencia terrorista tenga un programa político y carezca de objetivos lucrativos, y solo participe en actividades criminales por necesidades logísticas a diferencia de los criminales organizados ${ }^{76}$. Tamara Makarenko ha identificado siete tipos de relaciones que denomina el continuum crimen-terror y pone de manifiesto que el crimen organizado puede necesitar desarrollar alianzas con grupos terroristas, o incluso utilizar tácticas terroristas con fines operacionales. Igualmente, los grupos terroristas pueden desarrollar alianzas ocasionales con grupos criminales y/o llevar a cabo actividades criminales con fines operativos. Por razones de carácter logístico, Al Qaeda buscó la colaboración de grupos de criminales kosovares o mafias rusas, y los traficantes de cocaína del Sahel pagan a grupos terroristas para atravesar sus territorios y obtener protección. También se dan los casos

73 Djurdjevic-Lukic, S. y Dimitrijevic, V., «Human Security and Peace-Building in the Western Balkans», en BenedeK, W., DaAse, Ch., Dimitrijevic, V. y VAn Duyne, P. (eds.), Transnational Terrorism, Organized Crime and Peace-Building, Nueva York, Palgrave Macmillan, 2010, pp. 17-37.

74 BenedeK, W., «The Human Security Approach to Terrorism and Organized Crime in Post-Conflict Situations», en BenedeK, W., DaAse, Ch., Dimitrijevic, V. y Van Duyne, P. (eds.), Transnational Terrorism, Organized Crime and Peace-Building, op. cit., pp. 3-16.

75 De la CoRTE IBÁÑEz, L., "¿Hasta qué punto convergen el terrorismo global y la criminalizada organizada?: Parámetros generales y escenarios críticos», Revista Electrónica del Instituto Español de Estudios Estratégicos, 2013, pp. 4-5 (http://revista.ieee.es/index.php/ieee/article/view/41).

${ }^{76}$ MakarenKo, T., «The Crime-Terror Continuum: Tracing the Interplay between Transnational Organized Crime and Terrorism», Global Crime, vol. 6, 2004, núm. 1, pp. 129-145. 
de la contratación de servicios criminales por parte de grupos terroristas para perpetrar secuestros ${ }^{77}$.

35. Sin embargo, en ese continuum también se dan otros escenarios en los que la relación se hace más fuerte. Se trata de situaciones en las que los grupos terroristas cometen delitos con fines políticos o llevan a cabo una especie de terrorismo comercial. Este escenario es una especie de agujero negro en el que la naturaleza de ambos actores se diluye ${ }^{78}$. Cuando las células de grupos terroristas empiezan a desarrollar y a perseguir sus propias agendas, las necesidades de cooperación con el crimen organizado aumentan y pueden conducir a una hibridación de naturaleza difícil de identificar debido a la autonomía de objetivos, financiación y actuación de estas células. Por tanto, la falta de jerarquía favorece la hibridación entre perfiles medio-bajo de criminales y terroristas que pueden tener lazos familiares, de amistad o, incluso, religiosos o culturales.

36. En este sentido resulta difícil diferenciar los fines políticos o criminales en algunos casos, como los casos del EIIL en Siria, los Talibanes en Afganistán y Al Shabbaab en Somalia ${ }^{79}$. En la misma línea, Matthew Levitt señala que Hezbolá es hoy en día uno de los mayores exportadores de drogas desde América Latina a Europa, así como una de las mayores organizaciones de lavado de dinero del mundo ${ }^{80}$. Este modelo de hibridación necesita un contexto determinado para poder hacerse más intenso, y si los Estados frágiles han alcanzado la consideración de fallidos parece ser el más adecuado. La falta de instituciones que controlen el territorio y la población hacen que los grupos criminales se apoderen del funcionamiento económico del Estado y las organizaciones terroristas ofrezcan alternativas de gobierno sobre la base de los principios fundamentales en los que se sustenta el ideario político-religioso que promueven. Esta es una relación simbiótica hasta que los modos de actuación y los objetivos generales de ambos grupos se fusionan y se hibridan ${ }^{81}$.

37. Louise Shelley y John Picarelli también creen que las relaciones entre ambos tipos de organizaciones se están volviendo cada vez más complejas y que las líneas que diferencian a un tipo de organizaciones de las de otro tipo son cada vez más difusas, porque tanto criminales como terroristas están co-

77 Así lo señala el Informe del secretario general sobre la amenaza de los terroristas que se benefician de la delincuencia organizada transnacional, doc. cit, nota 71, pp. 4-5.

78 MaKarenKo, T., op cit., nota 76, p. 138.

79 La Oficina de Naciones Unidas contra la Droga y el Delito (UNODC) calcula que, a nivel mundial, circulan entre 460-480 toneladas de heroína, de las cuales 380 se producen a través del opio afgano y que, en 2009, los talibanes afganos ganaron unos 155 millones de dólares gracias al comercio de opiáceos (Informe del secretario general sobre la amenaza de los terroristas, doc. cit., nota 71, pp. 6-9).

80 LevitT, M., «Hezbollah: Financing Terror through Criminal and Enterprise», Testimony before the Committee on Homeland Security and Governmental Affairs, US Senate, vol. 25, 2005.

81 Peter Lupsha identifica modelos de crimen organizado predatorio protagonizados por bandas que quieren ampliar su territorio y negocios en Estados que mantienen el monopolio de la fuerza. Un modelo de carácter parasitario en el que el crimen organizado corrompe a algunos sectores y personas del Estado, y este se pone al servicio de la delincuencia como es el caso de los narcoestados (LUPSHA, P. A., «Transnational Organized Crime versus the Nation-State», Transnational Organized Crime, vol. 2, 1996, núm. 1, pp. 21-48). 
menzado a trabajar juntos hacia sistemas híbridos debido a la convergencia organizativa en modelos más descentralizados ${ }^{82}$. De hecho, la dinámica de cambio y transformación de ambos actores y de sus relaciones debería ser objeto principal de atención, sobre todo teniendo en cuenta que ambos comparten información y tácticas operativas ${ }^{83}$.

38. Un ejemplo muy significativo de esa tipología de cooperación es el de la región del Trans-Sahara, donde el contrabando siempre ha sido una actividad muy amplia desarrollada por las comunidades libias fronterizas bajo el consentimiento y control informal del gobierno de Gadafi. Sin embargo, desde la caída del régimen, el volumen de contrabando de cigarrillos, drogas, armas y personas migrantes han incrementado de manera exponencial. Como señala The Global Initiative Against Transnational Organized Crime, en su informe sobre el crecimiento de la economía criminal y la financiación del terrorismo en la región del Sahara, el incremento del flujo de dinero en la región se debe al contrabando que pasa por el Sahel hasta el norte de África ${ }^{84}$. Gracias a la protección de los grupos terroristas que controlan zonas de Libia y del Sahel y se lucran con su participación en el negocio, como son AnsarEddine, Boko Haram y Ansar-al Sharia, las organizaciones criminales se han hecho con las actividades ilícitas en Mali, Nigeria y Libia, colaborando con milicias tribales o clanes.

39. El informe del United States Institute of Peace, sobre la base de la información recogida de 200 entrevistas desarrolladas a través de un trabajo de campo por todo el territorio libio, también pone de manifiesto una situación de cooperación entre grupos terroristas y criminales organizados para el desarrollo de un tráfico interconectado de inmigrantes, armas, drogas y otros objetos susceptibles de contrabando ${ }^{85}$. Esta cooperación ha creado una especie de industria de "protección criminal» por parte de grupos armados, en su mayor parte calificados como terroristas, que ha sacado el mejor partido a la situación de transición que vive Libia, instaurando un modelo de gobernanza gracias a la colaboración con los criminales organizados y otros actores armados a lo largo de toda la zona trans-sahariana, que logran hacer llegar los productos y las personas con las que trafican a la costa libia y a las zonas fronterizas ${ }^{86}$.

82 Estas conclusiones han sido obtenidas de la investigación realizada por ambos autores sobre la triple frontera entre Paraguay, Brasil y Argentina y la convergencia entre grupos terroristas y criminales en Oriente Medio que comparten el interés por atacar objetivos israelíes (SHELLEY, L. I. y PICARELLI, J. T., «Methods and Motives: Exploring Links between Transnational Organized Crime and International Terrorism», Trends in Organized Crime, vol. 9, 2005, núm. 2, pp. 52-67).

83 Stohl, M., "Networks, Terrorists and Criminal: The Implications for Community Policing», Crime Law Soc. Change, vol. 50, 2008, núms. 1-2, pp. 59-72.

${ }^{84}$ Libya: A Growing Hub for Criminal Economies and Terrorist Financing in The Trans-Sahara, Policy Brief, The Global Initiative Against Transnational Organized Crime, 11 de mayo de 2015 (http:// globalinitiative.net/wp-content/uploads/2015/05/2015-1.pdf).

85 Shaw, M. y Mangan, F., Illicit Trafficking and Libya's Transition. Profits and Losses, Peaceworks, United States Institute of Peace, 2014 (https://www.usip.org/sites/default/files/PW96-Illicit-Traffickingand-Libyas-Transition.pdf).

${ }^{86}$ Ibid., pp. 4-14. 
40. El negocio no solo incluye drogas y el armamento que poseía el régimen de Gadafi, cuya venta ha generado grandes beneficios y ha alimentado conflictos en Estados vecinos, la actividad más lucrativa es el tráfico de personas migrantes a lo largo de la costa del norte de África, que alcanza un valor de entre 255 a 323 millones de dólares anuales solo para Libia, del total del negocio «trans-sahariano». La agencia europea FRONTEX calcula que un 60 por 100 de los emigrantes que cruzan ilegalmente el Mediterráneo lo hacen a través de Libia ${ }^{87}$. De hecho, muchas tribus nómadas, como los Tuareg o los Tebu, colaboran con el crimen organizado en el tráfico ilegal de emigrantes africanos hasta llegar a territorio tunecino o libio y, en esas rutas, los grupos terroristas siguen teniendo un gran control y participan de los beneficios. AQMI controla buena parte de las actividades ilícitas en el Sahel, pero el grupo libio Al-Mourabitun, liderado por Mokhatr Belmokhtar, controla buena parte del tráfico de cigarrillos de África y ahora, también, el de cocaína. En los últimos años la ruta de la cocaína procedente de Colombia ha cambiado y se introduce a través de Guinea-Bisau al resto de África y a Europa, y se calcula que genera unos beneficios de entre 10 y 20 millones de dólares anuales solo para los grupos que participan en la zona del Sahel, Argelia y Libia ${ }^{88}$.

41. Es evidente que este tipo de colaboración es la más cercana al modelo de hibridación comentado anteriormente, ya que independientemente de los objetivos que criminales organizados o grupos terroristas esgriman para justificar su existencia e identidad, los criminales logran incrementar sus actividades gracias al control que los terroristas ejercen sobre la población y el territorio a través del terror. Y los grupos terroristas garantizan su existencia, su actividades e, incluso, la aceptación de la población, utilizando los beneficios obtenidos de la actividad criminal. Además, los perfiles de los individuos que componen ambos grupos son muy similares, incluso los grupos criminales reclutan a individuos que pasan a formas parte de las filas de grupos terroristas y, a su vez, estos participan en la protección y de las actividades criminales. En este sentido, las características de la membresía ayudan aún más a que se produzca el modelo de hibridación.

42. El análisis realizado, en 2016, por el International Centre for The Study of Radicalization and Political Violence pone de manifiesto que la convergencia entre estas organizaciones no es la única, los individuos cada vez tienen un perfil más híbrido y pueden ser miembros de ambos tipos de organizaciones. En concreto, el estudio se basa en el análisis de los antecedentes penales como criminales comunes que poseen la mayor parte de los yihadistas europeos. De los 79 perfiles de individuos estudiados, 45 ya habían sido encarcelados por delitos comunes, que no superaban los diez años de prisión, antes de haber sufrido un proceso de radicalización y entrar en una organi-

87 European Border and Coast Board, Risk Analysis 2017 (http://frontex.europa.eu/assets/Publications/Risk_Analysis/Annual_Risk_Analysis_2017.pdf).

88 En el marco del Instrumento de Estabilidad y el Plan de Acción Global de la UE en la Lucha contra el tráfico de la ruta de la cocaína se han identificado nuevos mercados, rutas y alianzas entre los grupos del crimen organizado de América, Europa y África (https://cocaineroute.eu/). 
zación terrorista ${ }^{89}$. El fenómeno de criminales que se convierten en terroristas no es actual, pero sí parece haberse incrementado, porque la narrativa yihadista ofrece a los delincuentes la posibilidad de redención, al tiempo que pueden seguir desarrollando actividades criminales bajo una legitimación religiosa. Los criminales que pasan a las filas de grupos terroristas ofrecen conocimientos sobre el acceso a armas, capacidades logísticas y operativas y familiaridad con el uso de la violencia, lo que redunda en mayores posibilidades de conseguir fondos para la financiación de la organización terrorista ${ }^{90}$.

43. Independientemente de cuál sea la tipología de relación que pueda establecerse entre ambos ANEV, lo cierto es que el origen de estas relaciones consiste en que el terrorismo es capaz de asumir la necesidad de perpetrar actividades de carácter delictivo y eso facilita el que puedan desarrollar una colaboración, a pesar de que se asuma que la diferencia entre ambos actores consiste en la naturaleza económica de los objetivos del crimen organizado y en la naturaleza político-religiosa de los objetivos de los grupos terroristas ${ }^{91}$.

\section{CONCLUSIONES}

44. La evolución del sistema internacional ha facilitado la participación de actores no estatales en los distintos ámbitos de las relaciones internacionales, incluidos los ANEV. Los grupos de terroristas y criminales organizados también han conseguido espacios en los procesos de cooperación y conflicto. Análisis doctrinales, estudios de casos y manifestaciones de distintas organizaciones y agencias internacionales y nacionales alertan sobre un cambio en la naturaleza de las relaciones de cooperación entre grupos terroristas y criminales organizados, que potencian los peligros que de por sí ambos fenómenos suponen para la seguridad estatal, regional e internacional.

45. La falta de consenso a la hora de definir el terrorismo o la criminalidad organizada no supone un obstáculo para analizar la evolución de los modelos organizativos y de cooperación de estos grupos, si nos centramos en sus estrategias y acciones. A pesar de las diferencias que presentan en cuanto a los objetivos que persiguen en el plano internacional, comparten una serie de características, especialmente en los ámbitos orgánico y funcional, que potencian la profundización de sus relaciones, máxime si intervienen una serie de condicionantes que se han presentado en los últimos lustros.

46. El éxito de la lucha contra la financiación del terrorismo ha llevado a los grupos terroristas a buscar fuentes alternativas de financiación, y las alianzas con grupos de criminales organizados resultan muy ventajosas a la hora de conseguir recursos de actividades delictivas. Esta vía de financiación ha sido

89 Basra, R., Neumann, P. y Brunner, C., Criminal Pasts, Terrorist Futures: European Jihadists and the New Crime-Terror Nexus, Londres, ICSR King's College, 2016 (http://www.icsr.info), pp. 3-7.

90 Ibid., pp. 23-33.

91 MaKarenKo, T., op. cit., nota 76, pp. 140 y ss., y Von Lampe, T., Organized Crime. Analyzing Illegal Activities, Criminal Structures and Extra-Legal Governance, Thousand Oaks, Sage, 2016, p. 203. 
especialmente utilizada por los grupos pequeños o células dependientes de organizaciones mayores que participan en el denominado terrorismo global.

47. La mundialización de las comunicaciones y el intercambio de información facilitan los procesos de descentralización que han experimentado ambos actores violentos. Los grupos pequeños poseen mayores facilidades para establecer contactos horizontales y mayor flexibilidad para emprender procesos de cooperación, escapando de las estrictas jerarquías a las que estaban sometidos en la década de los noventa.

48. Por último, el aumento de la fragilidad de algunos Estados e, incluso, la descomposición de otros han dejado espacios de poder en al ámbito económico-social y en el monopolio de la fuerza que han acaparado grupos terroristas y criminales organizados. En estos contextos, la cooperación por motivos tácticos y logísticos existente se ha visto superada por otras modalidades de cooperación, llegando a modelos de hibridación, en los que resulta complejo distinguir la actuación criminal que persigue el lucro de la actividad terrorista, como uso de la violencia con fines políticos-religiosos. Los modelos de hibridación, como la expresión más avanzada de cooperación entre ambos actores, desdibujan las diferencias entre los objetivos y las actividades que normalmente les otorgan identidad propia.

49. Los modelos de hibridación también se potencian a medida que la membresía de ambos grupos pueda ser intercambiable, de manera que criminales se convierten en terroristas y los miembros de organizaciones terroristas asimilan una conducta predominantemente criminal, y en algunos casos permanentemente. El reclutamiento de delincuentes por células terroristas de Occidente es uno de los casos, pero también lo es la asistencia conjunta para el reclutamiento de miembros por grupos terroristas o criminales en el caso libio.

\section{RESUMEN \\ NUEVAS DINÁMICAS EN LAS RELACIONES ENTRE CRIMEN ORGANIZADO Y GRUPOS TERRORISTAS}

Independientemente de las disensiones a la hora de definir terrorismo y crimen organizado, los grupos que se identifican con estas prácticas tienen elementos en común que han facilitado sus relaciones de cooperación. Estas relaciones que se han ido adaptando y variando como resultado de la evolución del sistema internacional y los cambios en las características de sus actores. Factores como las consecuencias de la lucha contra la financiación del terrorismo, las posibilidades que ofrece la sociedad de la información y la comunicación en la descentralización de las organizaciones delictivas y terroristas o el incremento de los Estados frágiles han contribuido a intensificar y a transformar el carácter de las conexiones entre estos dos actores no estatales violentos. Este estudio aborda los cambios en la naturaleza y el alcance de los procesos de cooperación entre grupos terroristas y criminales organizados y los tipos de relaciones que pueden identificarse en la actualidad.

Palabras claves: actores no estatales violentos, crimen organizado, terrorismo, financiación, descentralización, Estados frágiles, cooperación, hibridación. 


\section{ABSTRACT \\ NEW DYNAMICS IN THE RELATIONSHIPS BETWEEN ORGANIZED CRIME AND TERRORIST GROUPS}

Regardless of the dissent in defining terrorism and organized crime, groups that identify with these practices have elements in common that have facilitated their cooperative relationships. These relations have been adapting and varying as a result of the evolution of the international system and changes in the characteristics of its actors. Factors such as the consequences of combating the financing of terrorism, the possibilities offered by the information and communication society in the decentralization of criminal and terrorist organizations, or the increase in fragile states have contributed to intensify and transform the dimension of connections between these two violent non-state actors. This study addresses changes in the nature and scope of cooperation processes between organized terrorist groups and criminals as well as the types of relationships that can be identified today.

Keywords: violent non-state actors, organized crime, financing, decentralization, fragile States, cooperation, hybridization. 